\title{
Too Young to Drink, Too Old to Dance: The Influences of Age and Gender on (Non) Rave Participation
}

\author{
JULIE GREGORY \\ QUEEN'S UNIVERSITY (CANADA)
}

\begin{abstract}
In this article I argue that rave participation is best understood as a form of accommodative resistance. Such a framework, it is maintained, helps highlight the nuanced influences of normative social discourses in relation to people's experiences and descriptions of moving in, through and past active rave participation. Specifically, the research findings presented herein are based on ten women's narratives about their participation within Toronto's rave scene circa 1994 to 2000. As such, this research represents an effort to make these women's particular - yet conspicuously absent - experiences central to analyses of rave participation. More generally, it is an argument for the importance of engaging various interlocking social discourses - including, but not limited to age and gender - vis-à-vis people’s (sub)cultural experiences.
\end{abstract}

\section{Keywords}

accommodative resistance, age, feminist epistemology, HATE, gender, Toronto, PLUR

The purpose of this article is to argue that if we are to offer valid representations of (sub)cultural activities, we must analyze the "internal complexity" of these experiences (Wilson 2002: 376). ${ }^{1}$ To support this claim, I explore some of the ways age and gender emerged as influential factors with regard to ten women's past active "rave" participation in Toronto. ${ }^{2}$ More specifically, I discuss the importance of these social discourses in relation to interviewees' descriptions of their introductions to, sustained participation within and eventual disengagements from this scene. It is important to note that these divisions are made, not because they necessarily represent discrete phases in interviewees' rave-related trajectories, but because they draw out aspects of the particularly aged and gendered nature of interviewees' (non) rave participation.

The structure of this discussion is as follows. First, I introduce the epistemological rationales and research sample upon which the findings presented in this article are based (Gregory 2006). Second, a relational understanding of resistance is offered as a way of framing these findings. Third, the importance of age and gender a propos interviewees' past active rave participation is discussed. ${ }^{3}$ Finally, a review of the research findings and theoretically-informed suggestions for future research are offered. 


\section{Methodology}

\section{Epistemology}

Long ago, McRobbie and Garber (1991 [1975]) noted that women's experiences are often omitted from studies of youth cultures and that this under-representation both leads to partial understandings of these phenomena and reflects women's continued subordination in these (and other) cultural spaces. More recently, Pini has argued that it is not enough to point out that contemporary (sub)cultural activities continue to be male-centered; as she states,

failure to go beyond the levels of production and organization, to say more about other levels of event participation and other experiential sites, amounts to a failure to address the significance of club cultural involvement for the hundreds of thousands of women who regularly participate in dance cultures, and who claim that such participation is central to their lives, their friendships and their identities (2001: 7, original emphasis).

Put differently, overly structural representations of rave and club cultures tend to lead scholars to miss and/or gloss over female participants' specifically-located experiences.

One claim which can be read into these assertions is that women - by virtue of identifying and/or being read as such - tend to experience their social surroundings differently than those who are (read as) men/male. As such, scholars who relegate women's voices to the margins of their studies are implicated in the construction of partial knowledge(s) (see also, Smith 1987). In this sense, and contrary to some critiques of this "feminist standpoint" position (see, Harding 2004), focusing on their experiences is "not about exploring women's club cultural experiences simply for the sake of it, or simply because we do not hear enough about such experiences" (Pini 2001: 15, emphasis in original). On the contrary, the epistemological claim here is that "the stories raving women tell say a lot about available and emerging fictions of femininity" (Pini 2001:15; see also, Hutton 2004; McRobbie 1993; Pini 1997a).

To adopt a "feminist standpoint" in relation to raving practices, then, is not to claim to offer a definitively "female" account of rave; instead, it is to involve oneself with (re)writing individual experiences into the stories we tell about (sub)cultural life. More specifically, it is to highlight similarities and differences in the ways similarlylocated people experience their social worlds and to consider possible reasons for such experiences. According to this view, "it is not only that we can, but - as feminists - we must find ways of connecting 'theoretical' insights to popular cultural practice and discourse" (Pini 2001: 61, emphasis in original).

\section{Research sample}

As suggested above, scholars continually argue that women's experiences and voices are pushed to the margins of modern-day rave and club cultures and representations thereof (see also, Bradby 1993; Pini 1997b; Tomlinson 2002). This insight inspired me to conduct semi-structured, face-to-face interviews with women over the age of twenty-five years who actively participated in Toronto's rave scene for at least one year between 1994 and 2000, but who no longer considered themselves active rave enthusiasts. ${ }^{4}$ More specifically, I sought to explore some women's introductions to, sustained participation within and eventual disengagements from Toronto's rave scene. 
To achieve this goal, I employed opportunistic sampling methods. Logistically, this meant contacting women in my social circle who fit the study criteria. After asking these women if they would be willing to participate in my study, I requested that they pass along a Letter of Invitation to other women they felt may also be interested. This process generated six interviews. To recruit more interviewees, a mass e-mail describing the research was sent to everyone on my e-mail contact list. Responses were received from twelve women. For various time and geographical reasons, only four of these e-mails translated into interviews. In total, the preceding findings are based on ten interviews which took place between early January and late April 2006. As such, the following findings should be understood as exploratory in nature.

It is important to note that in addition to identifying as female, this research sample is quite homogenous in terms of interviewees' social locations - at the time of their interviews - in relation to age, race, ethnicity, sexuality, martial status and level of education. In terms of their past rave participation, however, interviewees' ages and geographical locations varied. For example, although all identified as once actively involved in Toronto's rave scene, only three (Penelope, Mystic, Princess) interviewees were living in Toronto when they were first introduced to rave. In addition, while some interviewees had been attending rave events for well over ten years at the time of their interviews, the timeframes and ages discussed by each woman ranged considerably, with Kickin' attending her first event in 1995 at the age of fifteen and Serendipity going to her first rave in 2000 at the age of thirty-three. Similarly, there was a great deal of variation in terms of the length of each woman's active participation, with four women actively attending raves for one year (Kickin', Curious, Molly and Penelope), three women for two years (Princess, Serendipity and Grrrl), two women for four years (Pink and Mystic) and one woman for six years (Cosmic). 5

Interviews ranged in duration from one to three hours. Each interview took place in a location interviewees chose because it was considered a safe space to meet with me (in most cases a stranger) to discuss potentially sensitive topics. During their respective interviews, participants were asked about their movements into, through and out of Toronto's rave scene. With participants' permission, interviews were taperecorded.

Age and gender emerged as significant influences in relation to these women's stories about becoming, being and ceasing to be active rave participants. For example, and as will be discussed, attending rave events was something many interviewees did with their closest female peers and something that they described as connecting them both to these friends and to their (often older) male partners. Following these conversations, however, it would be irresponsible of me to focus solely on these more positive descriptions of their past rave participation, thereby omitting discussion of the ways age- and gender-related discourses emerged in interviewees' narrations of who "does" and "does not" belong in rave spaces, for example. Arguably, while these less idealistic readings of rave rarely figure into academic analyses, they are important because they demonstrate that rave participation is understood and experienced as both liberating and constraining; as one interviewee explained, "There is a dark side to it [rave participation] but there's also so much positive” (Grrrl; see also, Hutton 2006). 


\section{Theory}

LeBlanc's (2001) review of the related subcultural literature leads her to two conclusions which are in keeping with the above discussion. First, she maintains, scholars rarely include female participants' voices in their accounts of subcultural activities. Secondly, she argues that it is not enough to acknowledge women's presence in these arenas; scholars must explore the reproduction of gender norms in these spaces and "young women's resistance to and reformulation of these norms" (8). LeBlanc writes:

Girls' subcultural participation has [usually] been described in primarily sexualized terms, with their constructions of deviance assumed to be sexual and conducted primarily through affiliation with a male member. And yet it is hard to imagine why girls would join, and remain, if they were only accepted as toys for the boys ... When researchers focus specifically on gathering first-hand accounts of girls' and women's positions in maledominated subcultures, they find that [their motives] are much more complex and central than was previously thought

(2001: 68).

Again, if taken seriously, these insights require scholars to think critically about the ways socially-embedded stereotypes and power relations shape the stories we (and others) tell about (sub)cultures.

This latter point speaks to a major debate that emerges in discussions about (sub)cultural resistance: how is one to measure and delineate acts as "resistant" and/or "political" and to what extent is intention necessary (Raby 2005)? According to Butz and Ripmeester (1999: 2), a significant result of this controversy has been to polarize "resistant acts" into two camps: "struggle[s] geared specifically towards transcendental social change on the one hand, [and] everyday forms of evading the effects of power on the other" (2). Clearly, however, these are difficult questions, ones that continue to evoke ongoing debate.

For example, efforts to interrogate the (non) political (which tends to be conflated with "resistant") significance of Toronto's rave scene, parallel these debates. On the one hand, claims have been made that ravers' political activism is "subconscious" insofar as their styles of dress, music, dance and drugs may be interpreted as evidence of a rejection of, and resistance to, dominant social norms (McCall 2001). On the other hand, scholars have asked if rave-goers have ever organized in ways that have directly challenged governmental policies (Wilson 2002, 2006) and/or if rave can be understood as a social movement (see also, Carrington and Wilson 2001). And while there are documented examples of Toronto-area ravers rallying against proposed laws that would restrict their rights to dance in particular time/spaces (see, Hier 2002; Marsh 2006), in keeping with these latter analyses, I maintain that if we are to offer valid representations of rave participation and if we are to draw out raves' political and/or resistant importance, we must examine the ways power and oppression, subjugation and resistance, intersect and shape both these spaces and people's related affiliations, experiences and stories (see also, Marsh 2005).

That said, the present study is informed by a relational - not Political with a capital "P" - understanding of resistance. In other words, underlying this exploration of the ways age and gender emerged as significant factors in interviewees' rave-related stories is acceptance of claims that "to limit our conceptualization of resistance to that which is confrontational or direct is to deny the more nuanced and creative ways in which subordinate peoples engage power" (Butz and Ripmeester 1999: 4). According 
to this understanding, power and resistance are present in all social interactions, structures and experiences. Thus, to call "resistant" only those acts that attempt to usurp power from those who are understood as "holding" it is to misunderstand both power and resistance (see also, Foucault 1990 [1978]).

In the context of the present study, this understanding of resistance/politics suggests that what is significant is not

how likely dance culture is to bring down capitalism or patriarchy, but at what precise points it succeeds [and] fails in negotiating new spaces. In particular, it is not a simple question of dance culture being 'for' or 'against' the dominant culture, but of how far its articulations with other discourses and cultures - dominant or otherwise - result in democratizations of the cultural field, how far they successfully break down existing concentrations of power, and how far they fail to do so (Gilbert and Pearson 1999: 160).

Following this argument, then, rave (and post-rave) scholars must acknowledge that "resistant" acts are always also implicated in power, and vice versa; we must, in other words, recognize that "power and resistance are ontologically inseparable ... [and thus] exist as conditions of possibility each for the other" (Butz and Ripmeester 1999: 2). Following this discussion, interviewees' descriptions of their experiences moving into, through and out of Toronto's rave scene are conceptualized as examples of accommodative resistance insofar as they can be read simultaneously as responses and challenges to normative age- and gender-related discourses. ${ }^{6}$

\section{Findings}

\section{Moving in}

A number of interviewees constructed their introductions to Toronto's rave scene as an extension of their female-dominated social circles and accompanying activities. For example, Curious explained that she began attending events at the age of sixteen after she and a female friend re-united:

In grade nine [this friend] came back to the same high school as I ... we started talking a little bit, realizing that we had interests. She was friends with these girls [who] went to raves and I wasn't. And then her and I started doing drugs together, and we both got invited [to a rave event] through her other friends.

Here, Curious describes common drug-use practices as that which connected her both to this girlfriend and to other female peers who eventually invited her to her first rave event.

Similarly, Kickin' described her introduction to the scene in the context of her past participation in music-related activities, female-dominated social circle and previous drug-use:

Kickin': I first started going to clubs young, twelve. I remember [this roller rink in my hometown] had a dance night, so I started doing that when I was twelve years old ... Then I met up with [another girl] in high school and she took me to my first rave.

Julie: Was she older, younger? 
Kickin': She was a year older ... I was in grade ten [and fifteen years old]. She was in [grade] eleven. It was in Toronto ... It was a Syrous party ... I remember that it was some guy who drove that was a friend of hers ... I honestly don't remember if it was my first time doing $\mathrm{E}$ [cstasy] or not, but I had done acid and stuff before.

As these findings suggest, despite some claims that drug-use is of peripheral importance to rave participation (for example, Hutson 2000), the majority of interviewees described drug-taking as a highly social activity, one that figured prominently in their initial attractions to rave. Indeed, this finding should not be surprising in light of other studies which (a) represent participation in Toronto's rave scene as intimately linked with drug-taking activities (see, Barrett, Gross, Garand and Pihl 2005; Weber 1999; Wilson 2002).

With regard to some of the ways age and gender figured into their first rave experiences, it is interesting to point out that nine out of ten interviewees described being invited to their first event either by female friends who were connected to the scene by older males or by older male rave-goers themselves. In particular, interviewees who lived outside of the city (all except Penelope, Mystic, Princess) and/or who began attending raves before they could legally drive (Curious and Kickin'), narrated being dependant on male connections to physically get to events. In this context, recall, Kickin's above description of being driven to her first event by "some guy" who was a friend of a (older female) friend.

While geographical location seems to have played a significant role in determining both the size and gendered nature of the group of people with whom interviewees attended rave events, and while being "under-age" seems to have compounded one's dependent position, this is not to say that the experiences of interviewees who were older and/or living in Toronto were not patterned in particular - even similar - ways (see, Gregory 2006). For instance, Princess lived in Toronto and went to her first event at the age of seventeen. Unlike her non-Torontonian counterparts, however, she traveled to the event on a shuttle bus with a co-ed group of friends. Nevertheless, like other interviewees, Princess described herself and her female companions as neophytes who went to these events with their more seasoned male friends and/or partners. ${ }^{8}$

There are many possible explanations for this finding. For example, given the timeframe about which interviewees spoke (1994-2000), it is likely that the changing nature of Toronto's rave scene was a factor in this trend; this was a period during which Toronto's rave scene was in a state of flux and change, purportedly becoming less "underground" (and male-dominated) and more "mainstream" (see, Hier 2002; Marsh 2005, 2006; Wilson 2002; Weber 1999; Silcott 1999). Given these claims, then, it is not entirely surprising that young, suburban women were learning about and being initiated into the scene by more "seasoned" men.?

Another tendency which might help explain this trend it that a number of interviewees constructed rave participation as an opportunity to solidify and/or pursue romantic, heterosexual relationships (see, Gregory 2006). ${ }^{10}$ Serendipity, Molly and Penelope, for example, described their introductions to rave in the context of their respective relationships with men already in Toronto's scene. Serendipity even candidly labeled her past active rave participation as "following the boy ... to Toronto." These possible explanations notwithstanding, the above analysis suggests that in addition to age and gender, sexuality, geography and time intersected in ways that similarly shaped these ten women's introductions to Toronto's rave scene (see also, Marsh 2005). 


\section{Staying in}

In addition to figuring into their introductions to the Toronto's rave scene, age emerged as an influential factor in several interviewees' explanations for why they began attending these events. For example, eight interviewees (all except Penelope and Serendipity) went to their first rave events (both from inside and outside of Toronto) when they were younger than nineteen years old. Of these eight women, five (Cosmic, Molly, Kickin', Curious and Mystic) constructed their active rave participation as a direct response to being under legal drinking age; they could not legally get into bars and clubs, but they could go to all-aged rave events and experiment with drugs. In the context of the above-discussed accommodative resistance framework, and contrary or in addition - to possible readings that these women were "toys for the boys" (LeBlanc 2001: 68), there is at least one other reading of these findings: interviewees were asserting their independence by finding ways of doing what they wanted (i.e. using their often older male acquaintances as means to achieve their desires to attend rave events). Indeed, many interviewees represented their initial and sustained rave participation as ways to resist normative social conventions that told them that because of their (predominantly young) ages, they could not experiment with mind-altering substances (including alcohol) and because they were (mostly young) women, they should not st(r)ay far from home, especially late at night.

Not only did interviewees construct rave participation as a means of challenging social conventions that constrained their particularly aged and gendered bodies, they also described active rave-going as a way to participate in - and feel part of - a community that is separate from, and resistant to, mundane "mainstream" life. This argument led at least two women to suggest that rave-goers are more likely to become addicted to the sense of belonging facilitated by such participation than to any associated drug-use:

Curious: I think that if you have anyone [who] loves to dance, [who] likes to do drugs, and you put them in a room full of people [who also enjoy those things], you feel like it's your family, that you belong there.

Kickin': I didn't really know anybody who was addicted to E[cstasy]. I think people were addicted to the feeling of $\mathrm{E}$ [cstasy] and I think people were addicted to ... the acceptance and ... having fun and feeling like they belong[ed] somewhere.

By representing rave-going within the context of feelings of alienation outside these spaces, these (and other) interviewees problematized and resisted what they understood as overly-condemning media representations of rave $(r)$ s that were so prevalent at the time they were active participants.

Paradoxically, in relation to this latter point, all ten women also described divisions within Toronto's rave scene - divisions which revolved around musical styles, but which were further divided according to people's drug choices, clothing styles, age, gender, ethnicity and, to a lesser degree, sexual orientation (see, Gregory 2006; Weber 1999; Wilson 2002; see also, Hutton 2006; McCaughan, Carlson, Falck and Siegal 2005; Reynolds 1999). In fact, all ten interviewees identified themselves not only as once "active ravers", but also as particular kinds of ravers: as junglists, fans of house music and "meth babies", for example. And, in many instances, interviewees rejected and criticized other rave participants' specific identifications as strongly as they embraced "their own". 
Consider, for example, that several interviewees evoked normative age- and gender-related discourses to construct themselves as different from "Candy Ravers". In these instances, interviewees drew on language that suggested that - unlike themselves and as evidenced by their clothing, dance and musical choices - Candy Ravers are "juvenile":

Kickin': Candy Ravers were the ones who were completely dressed up ... They were the ones who made it mainstream I think. ${ }^{11}$

Molly: The clothes were probably the biggest thing for me. I got way into the fashion and started dressing like a raver and wanted a piercing of course. Plus you always distinguish different groups of ravers and, you know, you identified yourself. I identified myself with the hard-house ravers, the real dancers that liked to get out and move, hated the Candy Ravers, hated them - couldn't stand them.

Mystic: You'd see people [Candy Ravers] wearing all these multi-coloured bracelets and lots of fun fur and - very childish stuff ... like they would carry a toy, like a doll with them or whatever. They were ... more into happy hardcore music and [had] lots of jewellery on, and bright colours [and] really big, baggy pants.

Princess: Well there's Candy Ravers who often wear brighter colors and had pacifiers and wore fuzzy pants and liked glow sticks and stuff and they were more often listening to house or trance, or happy hardcore and our friends definitely never liked trance or happy hardcore, maybe some house. So, those people were over here and we were over here.

As evidenced above, Molly was the most vocal and passionate of interviewees with regard to this sub-group of rave-goers. Indeed, more strongly than any other interviewee, Molly represented age and gender as defining discourses with vis-à-vis who "does" and "does not" belong at rave events.

For example, consider Molly's explanation about why she "couldn't stand" Candy Ravers:

They were just so young and so fragile and I found it sad that they got into so many drugs so early in their life. I don't know why. We were all into the drugs, but they were such lost innocence. [They were] so young and should've been home playing with their Barbies, not snorting co[caine] and taking $\mathrm{E}$ [cstasy].

The particularly aged and gendered nature of Molly's above comments is made apparent by her reference to "Barbies" a quintessential - though not necessarily - young girls' toy. Indeed, like Molly, most interviewees rationalized their negative attitudes towards Candy Ravers by insisting that they were simply too young to be taking drugs.

There are at least three important points to be made in relation to this justification. First, there is the ironic contradiction that of the four women (Curious, Mystic, Grrrl and Kickin') who began participating in the scene at the age of sixteen or younger, all narrated concerns about the (perceived) young-ness of other rave-goers. One woman (Grrrl) even expressed immense concern about the possibility that one day she may have a daughter who will join a similar (sub)culture at a similar age.

Secondly, there was unanimous consensus amongst the six other interviewees who began attending when they were older than sixteen years of age that drug-taking is okay when one is older than nineteen years of age - which, perhaps not coincidentally, is the legal drinking age in Ontario. Thus, despite repeated stories of their own 
and friends' (all of whom were over the age of nineteen) occasional problematic "overuse" of drugs, these interviewees claimed that people tend to be more responsible drug-users when they are in their late teens. In this way, interviewees drew on normative discourses of (ir)responsibility and age-appropriate behaviour to condemn Candy Ravers.

The third point to which I draw readers' attention is more theoretical: interviewees projected a particularly young age onto Candy Ravers. Unless they spoke to individuals they understood as constituting this category of rave-goers, this is to say, interviewees could not be sure of the actual age of any particular Candy Raver; they could not "know" this person's age simply based on her/his physical appearance. Consequently, it can be argued that interviewees discursively constructed Candy Ravers as especially young and this construction flowed partly out of the symbolic value attributed to certain aspects of their appearance: brightly coloured, androgynous, baggy clothes, pigtails, toys, glow sticks and/or candy. From this reading, at the same time as it is important to note that gender is a shaky concept, too often equated with biological sex and/or exterior physical appearance, it is equally significant to acknowledge that conceptions of youth often are restricted to one's (perceived) age. In other words, age - like gender - is a discursive concept, often used to marginalize certain activities and/or identities as immoral and/or "deviant".

Ironically, and as suggested above, in other contexts, interviewees represented rave participation as attractive because it evoked certain aspects of childhood: senses of carelessness, pleasure and safety, for example (see also, Henderson 1993, 1994; McElrath 2005). In these instances, rave-going was described as a way to symbolically return to childhood. When juxtaposed with interviewees' depictions of Candy Ravers, however, it becomes clear that when rave-goers are understood not as symbolic children, but as actual children, their rave attendance is viewed by some people as a social problem and they become the objects of moral repugnance.

\section{Moving out}

As foreshadowed above, a number of interviewees contextualized their cessation of active rave participation within the context of increasing "adult" responsibilities. More specifically, many of them felt unable to reconcile active rave-going with their (present and/or future) roles as friends, daughters, mothers, students, employees, etc. And while my intention is not to belittle this explanation, it is interesting to point out that age and gender (again) figured prominently in these rationalizations. Consider, for example, Pink's claim that as she got older, she began thinking:

'What if I can't have kids because of what I've done,' you know what I mean? Like, I think women tend to start thinking about those things a lot more. I think they can only take so much. I think women at some point are like, 'ok, I've got to think about the rest of my life here'. Men, it takes them a lot longer ... to think that way.

According to this account, men are not necessarily exempt from having to think about responsibilities outside and/or beyond rave, but they are more likely than women to remain active in rave scenes - even as they age.

One explanation for this is that men have better chances of moving up the "rave hierarchy” (Hutson 2000). Cosmic, Princess, Pink, Penelope and Grrrl substantiated this claim when they explained that they have numerous male friends and acquaintances who hold positions "behind the scenes". Rather than using these findings as a 
starting point to acknowledge and/or critique the male-centered nature of Toronto's rave scene, however, interviewees tended to reproduce explanations which value women based on their physical appearance. ${ }^{12}$

According to Cosmic, for example, "the women fall by the wayside because women age terribly bad in the scene". She continued,

I think that drugs have a more ageing effect on women and prettier women come and the guys get older and they bring in the young pretty girls ... Women don't look good older in the scene. The men can age because they can always attract the pretty girls, who brought us into the scene and it just goes like that.

Certainly, discourses which construct women as particularly misplaced as rave promoters, DJs and participants must be read as more than highlighting the conclusion that men have better chances than women of moving up the rave hierarchy; they also can be understood as emanating from and reinforcing dominant ageist and patriarchal power relations.

In this context, one of the stories offered by a woman in Pini's (2001) sample emerges as particularly fascinating. Amy is described as a 32-year-old woman who constructs rave participation as the only thing that brings her pleasure. As such, Amy is torn by wanting to remain an active rave participant despite knowledge that people tend to understand rave participation as "juvenile". Notwithstanding the gratification she receives from rave, Amy rationalizes that to avoid looking like a "saddie", she knows she will soon have to quit raving (100). ${ }^{13}$

Within this same context, consider Pink's explanation as to why she ceased to be an active rave-goer:

I came home from a party and I looked in the mirror and I thought I was ... an old lady I had gray and green hair. I just looked at myself and that was when I made a decision to not do it anymore and if I did, it was going to happen very, very rarely, which it has since then.

When probed further, Pink explained:

I didn't have a boyfriend throughout the whole thing and I was twenty-three, twenty-four coming out of it ... I just wanted to find somebody who I was going to fall in love with and start thinking about my future and being in that scene I didn't think I was capable of moving on with the rest of my life. I thought that if I continued on anymore... I would end up lonely and [have] a sad life. (emphasis added)

Not only do these comments construct older female rave-goers as misguided; they also resonate with, and highlight the importance of, claims made by other interviewees.

First, interviewees tended to construct rave participation (likely because of its links with drug-use) as not conducive with parenthood (often described as the goal of adulthood). For example, Penelope stated that "there were a few people that we knew who did have kids and would still go out and party and we never thought it was a responsible thing to do; so I think it's just one of those things that ends when you have kids". A second, and clearly related, argument interviewees made is that rave participation must be understood and experienced as a phase; as Pink said, "I think that you should get out of the scene at a certain age ... I think that it should be a phase". A third argument emerging from these discussions is that although rave participation (and 
related activities) may be more appropriate for older, more mature participants than for younger ones (recall above discussion regarding Candy Ravers), there nevertheless comes a time when participants - especially women - become too old for rave participation. Again, the claim here is not that interviewees' understandings that they will eventually have to relinquish their (active) rave participation are necessarily invalid; instead the point is to problematize findings that interviewees see their situated identities as aging women - as eventual mothers, wives and/or partners - as necessarily incongruent with rave participation. ${ }^{14}$

This so-called "necessity" gets called into question by findings that some women can, do and will, balance their rave and non-rave activities. For instance, analyzing interviews with two women in her sample who are mothers, Pini finds,

One aspect of these women's self-management in relation to drug use becomes clear in their descriptions of how their time (their weekends) is organised so as to allow an appropriate period during which to 'come-down'. The management of 'come-down' is most clearly manifest in their negotiations of the cross-overs between raving and motherhood (1998: 175).

According to this analysis, while maintaining a rave-related social world and/or identity can require - perhaps especially for mothers - "rigorous management of time, energy, money and pain", some women understand these as acceptable trade-offs for the pleasure with which rave-going provides them (Pini 1998: 172).

Turning to interview data from the current study, Serendipity was the only interviewee who had both children and a full time career during her period of active rave participation. In keeping with Pini's (2001) argument that rave participation can offer women a much needed move from home (i.e. the domestic sphere) to house (a reference to house music, a genre of "rave" music), for Serendipity rave participation provided a break from her "home" life - a chance to evade the responsibilities associated with motherhood, even if only temporarily. This is not to say, however, that as a mother and a relatively older raver, her rave attendance was not a source of serious concern. In fact, because when she began attending raves (panicked) media representations were her only source of knowledge, Serendipity described constantly feeling concerned about what she understood as her conflicting roles as a mother and a "raver" - an identity she conflated with "drug-user". Despite these concerns, however, rave-going provided Serendipity - and other interviewees - with intense "spiritual" feelings of being connected with herself and the people around her (see also, Hutson 2000; Malbon 2005; Takahashi and Olaveson 2003; St John 2004). For these reasons, Serendipity strove to manage these "conflicting" aspects of her life and, for the most part, she found that being a mother and an active rave participant were not necessarily incongruent (see also, Gregory forthcoming).

\section{Looking ahead}

In summary, what I found as I spoke with interviewees about their rave-related trajectories is that while women do participate in rave and post-rave scenes, many of them continue to do so in "marginal or at least highly patterned ways" (McRobbie and Garber 1991 [1975]: 211).213). Again, this is not to say these women do not - or cannot - derive immense pleasure from their rave-related experiences and/or identities. On the contrary, the purpose of this article is to highlight the finding that as interviewees 
reflected on their movements through Toronto's rave scene, they drew on and reproduced age- and gender-related discourses which were simultaneously liberating and constraining (see also, Gotfrit 1991).

Recall, for example, that interviewees constructed their rave participation as both a way to resist normative discourses that raving (and related activities) is inappropriate, especially for young women and as - at least initially - contingent on having (mostly) older male friends. In addition, when representing Candy Ravers and when rationalizing the "necessary relinquishment" of their active rave participation, the overwhelming majority of interviewees discursively constructed older and younger female rave-goers - including themselves - as particularly misplaced within rave. In this way, just as age and gender were major factors in terms of interviewees' initial involvement and subsequent active participation in Toronto's rave scene, so too did their intersections influence interviewees' decisions to cease that same participation.

Given these findings, while it may be fair to claim that rave-going fosters and is fostered by feeling of peace, love, unity and respect (PLUR) (see, Hutson 2000; Martin 1999; Weber 1999), analyses must not end here; following the above discussion, rave scenes and related experiences also must be understood as embedded in historical, political and discursive processes of exclusion and discrimination (see also, Saldanha 2000) - or what I term "HATE" (hostility, antagonism, tension and elitism). ${ }^{15} \mathrm{It}$ is in this sense that interviewees' past rave participation might best be understood as a form of accommodative resistance insofar as it both facilitated and challenged discursive representations of age and gender.

What this finding suggests is that while some interviewees understood their past rave participation as allowing their youthful selves to explore different/changing forms of femininity (see also, Bradby 1993), many of them also reproduced and internalized dominant discourses about what it means to be a "socially responsible" adult (see also, Pini 2001). Arguably, this inability for some women to imagine and/or accomplish a lasting, alternative "adult femininity" within rave should not be surprising; as numerous scholars have sought to illustrate, rave participants and their corresponding scenes are not cut-off from "outside" power relations (see also, Measham 2002; Thornton 1995). In keeping with these analyses, the findings presented herein suggest that once outside - and oftentimes inside - the rave and related spaces, women have to contend with the social meanings attributed to their specifically aged, gendered, sexualized and drugged bodies.

Clearly, however, because (like all of us) rave participants embody numerous social locations, the present discussion suggests a number of fruitful future research avenues: how, for example, do older women who continue to attend rave events negotiate these socially constructed discourses; in what ways might men be understood as experiencing rave spaces in similar and/or different ways from women; what roles might categories/discourses such as able-bodiedness, race and/or social class play in who does and does not participate in raves? Regardless of whether or not these particular questions are taken up, the present findings suggest that when studying rave and post-rave practices, scholars must continue to delve beyond romantic readings of raves spaces as pockets of time/space within which social differences are "eliminated through dance, drugs, and other rituals that transform structures of subcultural capital into anti-structure" (Hutson 2000: 44; see also, Redhead 1990; Rietveld 1998); they must also, this is to say, engage the numerous ways in which various interlocking social discourses - including, but not limited to age and gender - shape people's (sub)cultural experiences and affinities and the stories they tell about them. 


\section{Acknowledgements}

I would like to thank Dr David Butz and Dr Rebecca Raby for their supervisory support with the Master's thesis upon which this article is based. Thank you also to Samah Sabra, Graham St John and two anonymous reviewers for their extensive feedback and suggestions.

\section{References}

Barrett, Sean, Samantha Gross, Isabelle Garand and Robert Pihl. 2005. "Patterns of Simultaneous Polysubstance Use in Canadian Rave Attendees". Substance Use \& Misuse 40(9-10): 1525-37.

Bradby, Barbara. 1993. "Sampling Sexuality: Gender, Technology and the Body in Dance Music". Popular Music 12(2): 155-76.

Butz, David and Michael Ripmeester. 1999. "Finding Space for Resistant Subcultures." InVisible Culture: An Electronic Journal for Visual Studies 2(Winter): 1-19. $<$ http://www.rochester.edu/in visible culture/issue2/butz.htm $>$.

Carrington, Ben and Brian Wilson. 2001. "One Continent Under a Groove: Rethinking the Politics of Youth Subcultural Theory." Soundscapes: On-line Journal of Media Culture 4: 1-8. <http://www.icce.rug.nl/ soundscapes/VOLUME04/One_continent.shtml >.

Foucault, Michel. 1990 [1978]. The History of Sexuality: An Introduction, Volume 1. Trans. Robert Hurley. New York: Random House.

Gilbert, Jeremy and Ewan Pearson. 1999. Discographies: Dance Music, Culture and the Politics of Sound. London: Routledge.

Gotfrit, Leslie. 1991. "Women Dancing Back: Disruption and the Politics of Pleasure". In Henry Giroux (ed.), Postmodernism, Feminism and Cultural Politics, pp. 174-290. New York: University Press, 174-290.

Gregory, Julie. 2006. “Dancing Politics: Connecting Women's Experiences of Rave in Toronto to Ageism and Patriarchy". M.A. Thesis (Social Justice and Equity Studies), Brock University.

----. Forthcoming. “'I've Spent My Whole Life Preparing to Raise Teenagers': Links between Mothering and Raving". In Elizabeth Podneiks (ed.) Mediated Moms: Mothering in Popular Culture. (under review with McGill-Queen's University Press).

Harding, Sandra (ed.). 2004. The Feminist Standpoint Theory Reader: Intellectual and Political Controversies. New York: Routledge.

Henderson, Sheila. 1993. "Luvdup and De-elited: Responses to Drug Use in the Second Decade”. In Peter Aggleton, Peter Davies and Graham Hart (eds.), AIDS: Facing the Second Decade, pp.119-30. London: The Falmer Press.

----. 1994. "Time for a Make-over? Women and Drugs in the Context of AIDS". In Lesley Doyal, Jennie Naidoo and Tasmin Wilton, AIDS: Setting a Feminist Agenda, pp. 183-96. London: Taylor \& Francis Ltd.

Hier, Sean. 2002. "Raves, Risk and the Ecstasy Panic: A Case Study in the Subversive Nature of Moral Regulation". Canadian Journal of Sociology 27(1): 33-54.

Hutson, Scott. 2000. "The Rave: Spiritual Healing in Modern Western Subcultures". Anthropological Quarterly 73(1): 35-49.

Hutton, Fiona. 2004. "Up for it, Mad for it? Women, Drug Use and Participation in Club Scenes". Health, Risk and Society 6(3): 223-37.

----. 2006. Risky Pleasures? Club Cultures and Feminine Identities. Aldershot: Ashgate.

Leblanc, Lauraine. 2001. Pretty in Punk: Girls' Gender Resistance in a Boys' Subculture. New Brunswick: Rutger's University Press. 
Malbon, Ben. 2005. "Moments of Ecstasy: Oceanic and Ecstatic Experiences in Clubbing". In Ken Gelder (ed.), The Subcultures Reader, 2nd ed. pp. 419-509. London, Routledge.

Marsh, Charity. 2005. Raving Cyborgs, Queering Practices and Discourses of Freedom: The Search for Meaning in Toronto's Rave Culture. PhD Dissertation (Musicology and Ethnomusicology), York University.

----. 2006. "Understand Us Before You End Us': Regulation, Governmentality and the Confessional Practices of Raving Bodies". Popular Music 23(3): 415-30.

Martin, Daniel. 1999. "Power Play and Party Politics: The Significance of Raving”. Journal of Popular Culture 32(4): 77-99.

McCall, Tara. 2001. This is not a Rave: In the Shadows of a Subculture. New York: Thunder's Mouth Press.

McCaughan, Jill, Robert Carlson, Russel Falck and Harvey Siegal. 2005. "From 'Candy Kids' to 'Chemi-Kids': A Typology of Young Adults Who Attend Raves in the Midwestern United States". Substance Use \& Misuse 40(9-10): 1503-23.

McElrath, Karen. 2005. "MDMA and Sexual Behavior: Ecstasy Users' Perceptions About Sexuality and Sexual Risk". Substance Use \& Misuse 40(9-10): 1461-77.

McRobbie, Angela. 1993. "Shut Up and Dance: Youth Culture and Changing Modes of Femininity”. Young 1(2): 13-31.

McRobbie, Angela and Jenny Garber. 1991 [1975]. "Girls and Subcultures". In Stuart Hall and Tony Jefferson, Resistance Through Rituals: Youth Subcultures in Post-War Britain, pp. 209-22. London: Routledge.

Measham, Fiona. 2002. '“Doing Gender' - 'Doing Drugs': Conceptualizing the Gendering of Drug Cultures". Contemporary Drug Problems. 29(2): 335-73.

Pini, Maria. 1997a. "Cyborg, Nomads and the Raving Feminine." In H. Thomas (ed.), Dance in the City, pp. 111-29. Basingstoke: MacMillian.

----. 1997b. "Women and the Early British Rave Scene". In Angela McRobbie (ed.), Back to Reality?: Social Experience and Cultural Studies, pp. 152-69. Manchester: University Press.

----. 1998. "Peak Practices': The Production and Regulation of Ecstatic Bodies". In John Wood (ed.), The Virtual Embodied: Presence/Practice/Technology, pp. 168-77. London: Routledge.

----. 2001. Club Cultures and Female Subjectivity: The Move from Home to House. New York: Palgrave.

Raby, Rebecca. 2005. “What is Resistance?”. Journal of Youth Studies (8)2: 151-71.

Redhead, Steve. 1990. The End-of-Century Party: Youth and Pop Towards 2000. Manchester: Manchester University Press.

Reynolds, Simon. 1999. Generation Ecstasy: Into the World of Techno and Rave Culture. New York: Routledge.

Rietveld, Hillegonda. 1994. "Repetitive Beats: Free Parties and the Politics of Contemporary DiY Dance Cultures in Britain”. In George McKay (ed.), DiY Culture: Party and Protest in Nineties Britain, pp. 243-67. London: Verso.

Saldanha, Arun. 2000. Music Tourism and the Factions of Bodies in Goa. Tourist Studies. 2(1): 43-62.

Silcott, Mireille. 1999. Rave America: New School Dancescapes. Toronto: ECW.

Smith, Dorothy. 1987. The Everyday World as Problematic: A Feminist Sociology. Boston: University Press.

St John, Graham (ed.). 2004. Rave Culture and Religion. London: Routledge.

Takahashi, Melanie and Tim Olaveson. 2003. "Music, Dance and Raving Bodies: Raving as Spirituality in the Central Canadian Rave Scene”. Journal of Ritual Studies 17(2): 72-96.

Ter Bogt, Tom and Rutger Engels. 2005. "Partying' Hard: Style, Motives and Effects of MDMA Use at Rave Parties". Substance Use \& Misuse 40(9-10): 1479-1502.

Thornton, Sarah. 1995. Club Cultures: Music, Media and Subcultural Capital. Hanover: University Press Of New England. 
Tomlinson, Lori. 2002. “This Ain't No Disco'.. Or is it? Youth Culture and the Rave Phenomenon". In Jonathan Epstein (ed.), Youth Culture: Identity in a Postmodren World, pp. 195-211. Oxford: Blakwell.

Weber, Timothy. 1999. "Raving in Toronto: Peace, Love, Unity and Respect in Transition." Journal of Youth Studies 2(3): 317-36.

Wilson, Brain. 2002. "The Canadian Rave Scene and Five Theses on Youth Resistance”. Canadian Journal of Sociology 27(3): 373-412.

----. 2006. Fight, Flight or Chill: Subcultures, Youth and Rave in the Twenty-First Century. Montreal: McGill-Queen's University Press.

\section{Author Biography}

Julie Gregory is a $\mathrm{PhD}$ candidate in the Sociology Department at Queen's University in Kingston, Ontario, Canada. Her research interests continue to lie at the intersections of the sociology of knowledge, feminism and the social construction of "youth".

\section{Notes}

1 Use of "(sub)culture" throughout this article is meant to highlight the position that it is naïve to understand any social phenomenon - including rave - as completely detached from "mainstream" culture.

2 I am aware that the term "rave" may appear dated to some readers. Nevertheless, I use this terminology because it situates this analysis within a particular time/place (Toronto's electronic dance music scene circa 1994-2000) and because it is the term used both by interviewees and the Canadian scholars to whom I refer.

3 Herein, active rave participation is taken to mean that interviewees both attended raves on what they understood as a regular basis (at least once a month) and began to identify themselves, to varying degrees, as "ravers".

4 Notably, each woman's understanding of "no longer active" varied from not attending a rave event in the last eight years to still going to "rave-type" events, but on a much less regular basis than in the past.

5 Cleary, these names are pseudonyms, which were chosen by interviewees for reasons including that they are the names they always wished they had, they are their past "raver/dj name," was and the are the designations they felt best described their past active rave participation. In cases where interviewees found it difficult to decide on pseudonyms, these names were assigned by the researcher.

6 David Butz, personal communication with the author (St. Catharines, Ontario).

7 In Serendipity's case the men with whom she attended her first event were significantly younger than her.

8 This trend is not explored in the literature, with the exception of Wilson (1999) who alludes to this finding when he explains that amongst the reasons interviewees gave for their initial participation in Toronto's rave scene was the claim that "a boyfriend or girlfriend was already involved and influenced the decision to try it" (126). Significantly, Wilson does not pursue this finding, however, except to say that in every interview he conducted "it was always a male who was involved first" (126, emphasis added).

9 Thank you to an anonymous reviewer for suggesting that, according to this logic, this may mean that the experiences of women getting into the scene today are less likely to be gendered in the same ways described herein. 
10 Thank you to another anonymous reviewer for asking me to draw out the finding that interviewees' sexual orientations may have been a major influential factor explaining their introductions to the scene by (older) men.

11 It is important to note that here Kickin' is drawing on an arguably elitist ethos common amongst some rave-goers that to be(come) "mainstream" is to lose the subversive edge which is a subculture's raison d'être. In this sense she, clearly, is snubbing Candy Ravers.

12 Grrrl's comments about being a DJ within the scene are an exception here. When asked about this experience, for example, she explained that in addition to feelings of empowerment, this experience provided "an awakening for how much of a struggle women still have" within and outside the scene.

13 Pini (2001) does not define "saddie", but I venture to argue that this is a slang term for "pathetic", "pitiable" and/or "useless".

14 Interestingly, and contrary to the suggestion that older women's bodies just cannot handle the same amount of drugs as they once could, Ter Bogt and Engels (2005: 1492) find that in terms of women's drug-use, "age was a relevant factor, with older women experiencing less negative outcomes".

15 I devised this acronym to encapsulate arguments that raves do not escape dominant discriminatory practices and discourses as suggested by (overly optimistic) readings of rave as epitomized by Peace, Love, Unity and Respect (PLUR) (see, Gregory 2006). 